\title{
RESENHAS
}

\section{DANSEREAU, Pierre. A Terra dos homens e a paisagem interior. Belém, NAEA/UFPA, 1999}

\author{
Elaborada por Elder Figueira \& Roseilza do Vale*
}

Para o autor, é necessário que cada indivíduo tenha consciência de que suas ações influenciam enormemente sobre o meio ambiente, e de que precisamos modelar e por em prática novas leis de manejo, e desenvolvermos um plano de gestão onde o homem relacione-se com o meio, do qual faz parte, de maneira racional. Conhecere interiorizar a paisageméfundamental para o desenvolvimento de uma eficiente gestão. Ele relaciona no livro três conceitos fundamentais: ecologia, desenvolvimento e ecodecisão. Tenta-se encontrar um ponto que relacione os conhecimentos científicos dos homens, com as reflexões pessoais do indivíduo e do povo como um todo, coloca-se em discussão o fato de que o homem age modelando a paisagem segundo suas percepções interiores.

O livro é dividido em seis capítulos, sendo que cada um aborda pontos distintos da problemática do relacionamento entre o homem e sua percepção do meio. O capítulo inicial diz respeito à percepção do homem com relação ao meio e como ele age segundo esta percepção, tentando modificá-lo para que ele consiga suprir suas necessidades de sobrevivência. No segundo capítulo são abordadas as formas de codificação que o homem faz do meio, e como essa codificação interfere em sua formação. Em seguida, no terceiro capítulo, a pesquisa é levada a foco, mostra como nós compreendemos a natureza e a consciência do lugar que ocupamos dentro dela. No quarto, tenta-se tecer a malha de como o homem implementa as forças para modelar o meio segundo suas percepções

" Os resenhistas são biólogos e atualmente fazem mestrado em Ecologia de Ecossistemas Costeiros e Estuarinos, Campus de Bragança, Universidade Federal do Pará. 
de necessidades. O quinto capítulo trata da necessidade de um planejamento renovado da ação do homem. O sexto capítulo enfoca a aplicação de nossos conhecimentos, segundo a atual situação do homem/natureza, e como devemos desenvolver uma gestão que mostre-se razoavelmente lícita à conservação do meio ambiente.

\section{Percepção em vista da sobrevivência}

Cada cultura têm sua percepção do seu meio ambiente material e a partir disso implementa suas ações, que se figura para cada um como ele próprio o vê. A percepção do ambiente é um fato mais cultural do que simplesmente uma situação pré-concebida.

Modernamente, a ciência colocou o homem no centro do universo, e tentou racionalizar todas as ações voltando-as para suprir as vontades da sociedade humana. Culturalmente, criou-se uma situação em que o ser humano pode julgarse supremo diante de toda a natureza, ele deixou de perceber que somente faz parte dela, que é apenas um complemento do meio, talvez um dos mais importantes, mas um entre muitos. Um outro extremo, o naturalista, supervaloriza a natureza esquecendo-se do homem, o que também não pode ser aceito. Há que se ter equilíbrio, e pensar que somos interdependentes.

A percepção do meio é primeiramente apresentada segundo uma questão de sobrevivência. O homem vê o mundo como ele o foi apresentado e como este foi vivenciado.

\section{Formação e educação para resgatar o conhecimento}

Os povos devem inicialmente conhecer o meio em que estão inseridos, para só então, conduzir sua utilização de forma adequada. Tenta-se aqui, uma maior elucidação das tarefas de descrição do meio ambiente pelos indivíduos que dele fazem parte. Pretende-se compreender essa descrição e os meios pelos quais as populações humanas as perpetuam.

Todo o discurso que cerca esta problemática pode ser reduzido em dois conceitos fundamentais: "inscape", que representa a paisagem interior de cada indivíduo ou grupo de indivíduos, e "landscape" a paisagem real. Sendo que toda a cadeia de pensamentos envolvidos une a ciência ecologia e sócio-economia, caracterizando o que podemos chamar de "ecologia humana".

O processo de interpretação do meio ambiente pelo ser humano inicia-se com a descrição, ou seja, a ação de dar nome às coisas, o que é puramente 
convencional. Os nomes são atribuídos segundo as necessidades e as associações sobre a realidade, o que em geral é uma situação imposta por toda uma cultura, e no mundo moderno a mídia responde por grande parte dessa disseminação, a maior parte das situações acontece inconscientemente, quase por abstração. $\mathrm{O}$ segundo passo para a compreensão do meio, é simplesmente conhecê-lo, e conhecer de uma forma tão específica que não deixe de lado sua generalidade. $\mathrm{E}$ por fim, como estas interpretações tornam-se comuns a um grupo? Em geral, na atualidade, a escola desempenha brilhantemente esse papel, coloca estas "verdades" para os indivíduos e com isso consegue perpetua-las.

A questão é que as informações são passadas sem muita preocupação ou críticas, a ecologia tornou-se mais política e religiosa do que merecia ser. $\mathrm{O}$ termo, perdeu seu verdadeiro sentido, tornou-se de certa forma banal.

\section{Em busca das forças da natureza}

A ciência ecológica atual deve ser encarada como uma questão científica/ econômica, o meio ambiente deve ser considerado de maneira interdisciplinar, pois justamente ele é a reunião e comunhão de todos os segmentos de uma comunidade. Todo um ecossistema, nada mais é do que um jogo econômico de competição e cooperação, os processos ambientais mostram-se em um ponto de equilíbrio entre essas duas realidades. O ser humano interfere nessa realidade e provoca alterações.

O homem deve ser percebido como um elemento do meio ambiente, $\mathrm{e}$ como todos os outros provoca alterações, o fato que no entanto deve ser discutido, é como esse elemento tenta agora controlar toda uma cadeia de maneira tão egocêntrica? Os ecologistas devem voltar-se agora à compreensão do papel do homem nesse contexto.

\section{O poder de transformar o meio ambiente}

O funcionamento de qualquer ecossistema acontece pela reciclagem dos recursos (elementos que contribuem de maneira diversa para o processo de reciclagem) realizados pelos agentes (são os organismos vivos que têm a capacidade de se envolver em diversos processos de extração, transformação, armazenamento, canalização e transporte dos recursos), através de processos (mecanismos pelos quais os recursos sofrem todas as formas de mudanças e de transformação) característicos de cada nível ou regime trófico (são mais ou menos claramente estratificados a medida que os processos de reciclagem levam 
os recursos de um estado para outro, isto é, do mineral ao vegetal, ao animal) na transferência de energia. Toda a ação que acontece sobre determinado recurso, geram produtos (são armazenados, ou perdidos ou investidos como recursos suscetíveis de serem reciclados), que são típicos do nível tráfico de onde provêm.

O ecossistema é composto por seis níveis tráficos: mineral, vegetal, animal herbívoro, animal carnívoro, investimento e controle. O autor cria uma representação do ecossistema bastante característica, e tenda com este modelo agrupar todos os processos envolvidos na reciclagem da energia. O modelo é denominado de Bola de Flechas, e é inovador quando apresenta os conceitos de investimento e controle, bem como quando incorpora ao meio ambiente a noção de "noosfera" (intrusão da vontade na natureza). O esquema é representativo de todos os ecossistemas existentes, no entanto vale ressaltar que cada ecossistema particular, demonstra dinâmicas diferentes que os caracterizam.

Segundo o autor o poder do homem sobre o meio ambiente é destacado por cinco fazes, compostas por 8 estágios: A fase Aé primitiva e contém os estágios 1. a colheita e 2. a caça e a pesca; a fase B é nômade - pastoril e contém o estágio 3. o apascentamento; a fase C é a do estabelecimento e contém o estágio 4. a agricultura; a fase Dé industrial e contém os estágios 5. indústria e 6. urbanização; a fase E é climato-cásmica e contém os estágios 7. controle climático e 8. fuga exobiolágica. Em cada fase é preciso entender o conhecimento, a utilização e o impacto.

\section{O propósito e o plano}

Devemos a partir deste ponto procurar entender como foi estabelecido pelo homem, o atual design do meio ambiente. Design este, que altera a natureza provocando um desequilíbrio urbano/rural e que é controlado pelo homem urbanizado, o qual age sobre toda a extensão dos ecossistemas, desde o desenvolvimento suburbano até as florestas longínquas. A ação humana pode modificar ou inverter o funcionamento dos seis níveis tráficos, e as espécies envolvidas com os ecossistemas precisam adaptar-se as novas estruturas que lhe são impostas.

Embora o homem urbanizado influencie direta e indiretamente na natureza, ele também depende dos recursos dos ecossistemas selvagens, pois a produtividade dos seus primeiros níveis tróficos é bastante reduzida o que é compensado por seus investimentos e pelo poder de controlar outros ecossistemas. As inter-relações que a sociedade humana mantêm com meio ambiente devem ser encaradas mais como uma questão ética, do que algo puramente convencional. 


\section{A gestão}

Nosso planeta vivencia uma situação bastante peculiar, de maneira geral podemos afirmar que ele é pouco habitado se levarmos em conta as extensões de terra ainda desocupadas, mas por outro lado as populações existentes enfrentam um grave problema no que diz respeito à super multiplicação humana, e por conseguinte uma necessidade cada vez maior de materiais de base, de produtos industriais e de elementos culturais. Como contornar esse dilema?

É bem verdade que políticas públicas de manejo ambiental não são por si só a solução para os problemas do meio ambiente, mas são uma importante alavanca para melhoria da situação atual em que vivemos, fornecem uma possibilidade de estimarmos qual a responsabilidade humana e social para com a conservação dos ecossistemas. É necessário que cada ser humano tenha plena consciência de seus deveres e direitos, o que se pode conceber como a "ética da terra".

Trata-se de uma obra original e extremamente valiosa, pois conduz à inclusão de novos conceitos dentro das ciências sociais e ecológicas, por tratar o meio ambiente tanto em seu aspecto biológico quanto humano. Mostra que os ecossistemas são interdependentes, e que o homem é um dos elos mais importantes dessa cadeia, e um dos poucos que possui o poder de manipular a natureza.

Esta obra mostra-se de especial interesse para pesquisadores de sociologia, sócio-economia, antropologia, etnografia, comunicação social e ecologia. É leitura adequada tanto para cursos de graduação como de pós-graduação, devido sua linguagem objetiva e multidisciplinar. 